\title{
HISTOPATHOLOGICAL CHANGES IN THE GASTRIC MUCOSA INDUCED BY CARBARYL TOXICITY: AN EXPERIMENTAL RAT MODEL
}

\author{
Muhammad Shahab Hanif', Muhammad Saqib Baloch', Kumayl \\ Abbas Meghji' ${ }^{\otimes}$, Ali Abbas', Sana Kashif', Rida Qureshi'
}

\begin{abstract}
OBJECTIVE: To observe the effects of carbaryl ingestion on morphology and histopathological changes in the gastric mucosa of albino Wistar rats.

METHODS: In this quasi-experimental study, thirty Albino Wistar rats were randomly distributed into three different groups i.e. group-A (control), group-B (experimental-I) and group-C (experimental-2). The division was based on diet and quantity of drug-induced given. Group-A rats were given normal chow feed along with clean water ad libitum only, while group-B and group- $C$ rats were given $2.5 \mathrm{mg} / \mathrm{kg}$ and $5 \mathrm{mg} / \mathrm{kg}$ body weight carbaryl mixed in their normal feed respectively. All rats were weighed before and after the experiment.
\end{abstract}

RESULTS: Pre-experimental total body weight (Mean \pm SD) of groups $A, B$, and C were found to be $245.7 \pm 6.1 \mathrm{gm}, 252.3 \pm 4.5 \mathrm{gm}$, and $239 \pm 6.7 \mathrm{gm}$ respectively. Group A (control rats) showed an increase in body weight, while a decline in body weight was observed in groups B $(203.43 \pm 12.57)$ and C (169.29 \pm 13.72$)$ [pvalue $=0.00 \mathrm{I}]$. Similarly, the mean stomach weights of all the experimental rats were also measured at the conclusion of the experiment and were found to be $3.8 \mathrm{I} \pm 0.20$ gm (group-A), $3.22 \pm 0.29 \mathrm{gm}$ (group-B) and $2.26 \pm 0.65 \mathrm{gm}$ (group C) [pvalue $=0.00 \mathrm{I}]$. Histology of gastric mucosa of group-A didnt reveal any changes. In experimental groups, localized foci of congested blood vessels and infiltration by acute inflammatory cells were observed in the basal portion of gastric glands. Normal tubular architecture of the gastric mucosal glands was distorted.

CONCLUSION: Carbaryl administration induces marked histopathological changes in the gastric mucosa with decline in body and stomach weight of experimental groups.

KEYWORDS: Carbaryl (MeSH); Gastric Mucosa (MeSH); Rats (MeSH); Histopathology (MeSH); Histology (MeSH); Insecticides (MeSH).

THIS ARTICLE MAY BE CITED AS: Hanif MS, Baloch MS, Meghji KA, Abbas A, Kashif S, Qureshi R. Histopathological changes in the gastric mucosa induced by carbaryl toxicity: an experimental rat model. Khyber Med Univ J 2020; I 2(2): | 37-42. DOI: I0.35845/kmuj.2020.19896.

\section{INTRODUCTION}

nsecticide poisoning is one of the most common causes of acute poisoning all over the world, affecting more than one million people per year and killing around 100,000 .' Farmers, field workers, people near agricultural farms and those being exposed to pesticides either directly or indirectly after consuming pesticidecontaminated foods are greatly at risk of pesticide toxicity. ${ }^{2}$ Globally, China and USA are among the top pesticides producing countries. ${ }^{3}$ Pakistan, being an agriculture-dependent country, uses large quantities of pesticides in the agriculture division making it second in the overall utilization of pesticides amongst the South Asian countries. ${ }^{3}$ Pakistan has imported around 13,000 tons of pesticides according to the economic survey of 2016-17.

Carbaryl (I-Naphthyl N-Methyl carbamate), often referred to as the universal garden and yard insecticide is frequently used all over the globe due to its strong actions on insects and its accessibility. ${ }^{4}$ In the past decade, about
I. Department of Anatomy, ISRA University, Hyderabad, Pakistan.

Email『: dr.kumaylabbas@gmail.com Contact \#: +92-32I-3012009

$\begin{array}{ll}\text { Date Submitted: } & \text { November 21, 2019 } \\ \text { Date Revised: } & \text { April 04, 2020 } \\ \text { Date Accepted: } & \text { April 08, 2020 }\end{array}$

3.9 million pounds of carbarylregistered products were sold in the United States of America, out of which more than 11 0,000 Kgs were utilized in California in 2004 alone. ${ }^{5}$ While the use of pesticides like carbaryl etc. in Pakistan is remarkably high owing largely to the agriculture sector, it serves as a double-edged sword, affecting more than 500,000 people with pesticides like carbaryl and agrochemical poisoning. However, latest data on the exact consumption, exposure and related complications in Pakistan is highly scarce. ${ }^{3,6}$

Moreover, researchers have uncovered its essence in organic products accessible in the market. ${ }^{7}$ It causes reversible inhibition of enzyme acetylcholinesterase and hence elevating the cholinergic effects in human beings up to toxic levels. ${ }^{8}$ It also has been regarded as a possible cancercausing pesticide in USA.' Moreover, carbaryl has also been rated as a potent immune-toxic agent and hence is responsible for causing various allergic reactions. ${ }^{10}$ Several studies have reported diverse adverse effects of carbaryl on different organs system of the body in both humans and animals. ${ }^{11-16}$

Despite the decline in imports of pesticides in Pakistan, carbaryl is still used in a significant quantity by the farmers in the country." Moreover, large quantities of these pesticides like carbaryl are also used in households, fumigation purposes etc. in Pakistan. This excessive use poses both direct and indirect repercussions on human health.

The digestive system plays one of the most vital functions in the maintenance of the homeostasis. Although there are numerous studies available describing the effects of pesticides like carbaryl on digestive system of various species of animal, specific studies pertaining to the 
TABLE I: POST EXPERIMENT BODY AND STOMACH WEIGHTS IN ANIMAL GROUPS (GRAMS) $(\mathbf{N}=30)$

\begin{tabular}{|c|c|c|c|c|}
\hline VARIABLES & GROUPS & MEAN & SD & P-VALUE \\
\hline \multirow{3}{*}{$\begin{array}{l}\text { Mean Body } \\
\text { Weight (gm) }\end{array}$} & Group A & 263.5 & 9.74 & \multirow{3}{*}{$0.001 *$} \\
\hline & Group B & 203.43 & 12.57 & \\
\hline & Group C & $169.29+$ & 13.72 & \\
\hline \multirow{3}{*}{$\begin{array}{l}\text { Mean Stomach } \\
\text { Weight (gm) }\end{array}$} & Group A & 3.81 & 0.20 & \multirow{3}{*}{$0.001 *$} \\
\hline & Group B & 3.22 & 0.29 & \\
\hline & Group C & $2.26+$ & 0.65 & \\
\hline
\end{tabular}

TABLE II: COMPARISON OF VARIOUS HISTOPATHOLOGICAL CHANGES BETWEEN CONTROL GROUP A AND EXPERIMENTAL GROUP B

\begin{tabular}{|c|c|c|c|c|}
\hline HISTOLOGICAL VARIABLES & & GROUP A & GROUP B & P-VALUE \\
\hline \multirow{2}{*}{ Venous Congestion } & Yes & I & 8 & \multirow{2}{*}{$0.007^{*}$} \\
\hline & No & 9 & 2 & \\
\hline \multirow{2}{*}{ Glandular Duct Dilatation } & Yes & $\mathrm{I}$ & 5 & \multirow{2}{*}{0.53} \\
\hline & No & 9 & 5 & \\
\hline \multirow{2}{*}{ Inflammatory Cells Infiltration } & Yes & $\mathrm{I}$ & 3 & \multirow{2}{*}{0.26} \\
\hline & No & 9 & 7 & \\
\hline \multirow{2}{*}{ Distorted Glands } & Yes & 0 & 4 & \multirow{2}{*}{$0.02 *$} \\
\hline & No & 10 & 6 & \\
\hline \multirow{2}{*}{ Cellular Swelling } & Yes & 0 & 4 & \multirow{2}{*}{$0.02 *$} \\
\hline & No & 10 & 6 & \\
\hline
\end{tabular}

TABLE III: COMPARISON OF VARIOUS HISTOPATHOLOGICAL CHANGES BETWEEN CONTROL GROUP A AND EXPERIMENTAL GROUP C

\begin{tabular}{|c|c|c|c|c|}
\hline HISTOLOGICAL VARIABLES & & GROUP A & GROUP C & P-VALUE \\
\hline \multirow{2}{*}{ Venous Congestion } & Yes & 0 & 5 & \multirow{2}{*}{$0.01 *$} \\
\hline & No & 10 & 5 & \\
\hline \multirow{2}{*}{ Glandular Duct Dilatation } & Yes & $\mathrm{I}$ & 5 & \multirow{2}{*}{$0.05^{*}$} \\
\hline & No & 9 & 5 & \\
\hline \multirow{2}{*}{ Inflammatory Cells Infiltration } & Yes & 1 & 6 & \multirow{2}{*}{$0.01 *$} \\
\hline & No & 9 & 4 & \\
\hline \multirow{2}{*}{ Distorted Glands } & Yes & 0 & 8 & \multirow{2}{*}{$0.00 I^{*}$} \\
\hline & No & 10 & 2 & \\
\hline \multirow{2}{*}{ Cellular Swelling } & Yes & 0 & 7 & \multirow{2}{*}{$0.001 *$} \\
\hline & No & 10 & 3 & \\
\hline
\end{tabular}

toxic effects of carbaryl to the gastric mucosa are limited. ${ }^{16,17}$ Since stomach serves as a reservoir of food, it is the most exposed part of the entire digestive tract to such poisons such as carbaryl.

Therefore; the objective of the current study was to observe the effects of carbaryl (in a dose response manner) on morphology and histopathological changes in the gastric mucosa of albino Wistar rats which serves as a model laboratory animal for human toxicity studies. $^{18}$

\section{METHODS}

This quasi-experimental study was conducted at the Isra University, Hyderabad, Pakistan in collaboration with the animal husbandry in Sindh Agricultural University, Tandojam, Pakistan from July 2018 to December 2018. Thirty Albino Wistar rats were picked using the standard power analysis sample size formula for animal studies. ${ }^{19}$ Rats were acclimatized for ten days then randomly divided into three groups. Group A (control), group B (carbaryl $2.5 \mathrm{mg} / 100 \mathrm{gm}$ body weight) and group C (carbaryl $5 \mathrm{mg} / 100 \mathrm{gm}$ body weight). ${ }^{20,21}$ Animals were handled according to the guidelines provided by the national research council for laboratory animals handling and as per rules maintained by the animal ethical committee in the animal husbandry of Sindh Agricultural University Tando Jam.

All animals were given a normal chow diet with clean water ad libitum for five weeks while the diet mixed with the crushed experimental drug was given to the experimental groups ( $B$ and $C$ ) animals for the same duration. The selection of the animals was based on the inclusion and exclusion criteria. All rats of 9-12 weeks old, 200 to 300 grams in weight without any apparent disease or deformity were included in the study. While all pregnant, sick and those rats not fulfilling the inclusion criteria were excluded from the study. The body weights of all group rats were recorded before the diet started. After the end of the experiment, the rats of all groups were weighed on electronic balance before sacrifice. The rats of every group were euthanized by placing them in an inverted glass jar containing cotton pieces soaked in chloroform. The stomach of all animals was resected and gastric contents were evacuated after giving incision from greater curvature and thoroughly washed and kept in 10\% buffered formalin. The stomachs of all rats were cut transversely through the body and were passed in alcohol of increasing concentration $(70 \%, 80 \%, 95 \%$, $100 \%$ ) and followed by two passes in xylene solution for removing excess alcohol. The gastric tissues were embedded in melted paraffin wax and after cooling, wax blocks were made. Four (4) micron thick sections were cut from wax blocks and the sections were mounted on glass slides. The slides were finally stained with Hematoxylin and Eosin and observed under light microscope (Olympus $\mathrm{BH} 2$ ) for histopathological changes in the gastric mucosa, which were verified and authenticated by a pathologist.

Data was analyzed on SPSS version 22.0. Quantitative variables were analyzed by one-way analysis of variance (ANOVA) while 

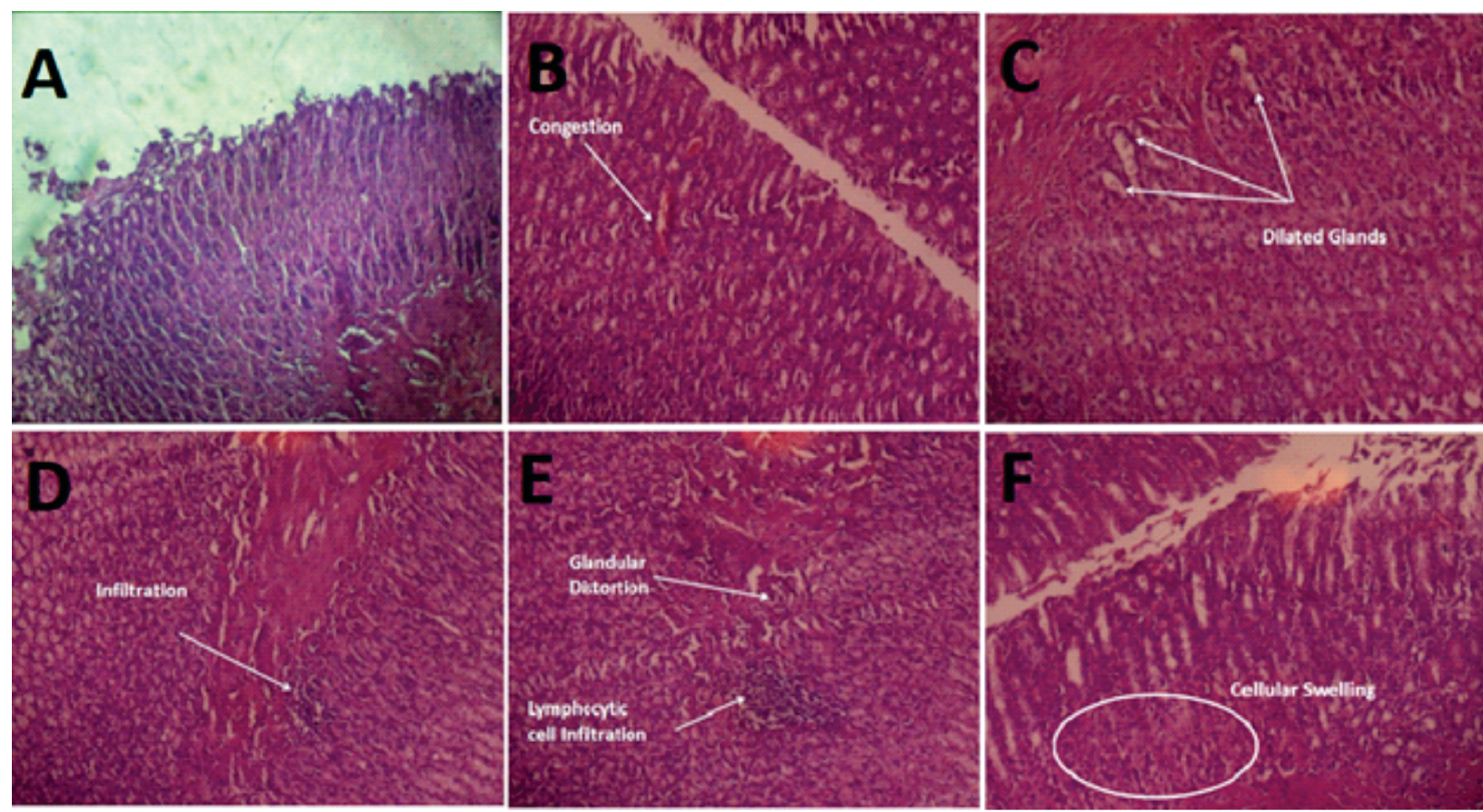

Figure I: Showing cut section of gastric mucosa of experimental animals $(H \& E) \times 200$. (A) Control group A rat showing normal architecture of the gastric mucosa with normal fundic glands. (B) group B rat showing gastric mucosa with venous congestion. (C) group $B$ rat showing gastric mucosa with dilatation of glandular ducts. (D) group B rat showing gastric mucosa with distortion of glands. (E) group B rat showing gastric mucosa with distortion of glands. (F) group B rat showing gastric mucosa with cellular swelling

histopathological variables were analyzed by Chi-square or Fisher's exact test where applicable. Statistical significance level taken at a $\mathrm{p}$-value $\leq$ 0.05 .

\section{RESULTS}

Pre-experimental total body weight (Mean $\pm S D$ ) of groups $A, B$, and C were found to be $245.7 \pm 6$. I gm, $252.3 \pm 4.5$ gm and $239 \pm 6.7 \mathrm{gm}$ respectively. At the conclusion of the experimental period, the body weights of all experimental animals were again measured and a marked difference in mean postexperimental body weight was observed in all groups. Group A (control rats) showed an increase in body weight, while a decline in body weight was observed in groups B $(203.43 \pm 12.57)$ a nd C (I69.29 \pm 13.72). However, the weight loss observed in group $C$ was more pronounced as compared with group $B$ $(p<0.05)$ [Table I].

Similarly, the mean stomach weights of all the experimental rats were also measured at the conclusion of the experiment and a statistically significant difference $(p<0.05)$ was observed among all experimental groups (Table I).

As shown in Figures $\mathrm{I}$ and 2, the microscopic examination of gastric mucosa of group A (control rats) did not reveal any histopathological changes however, various alterations were observed in both groups $B$ and $C$ as compared with group $A$. In groups $B$ and $C$, localized foci of congested blood vessels were observed in the basal portion of gastric glands. In addition, infiltration by acute inflammatory cells was observed within the deeper and lower portion of the gastric glands in the lamina propria. The normal tubular architecture of the gastric mucosal glands was also distorted with irregular margins and there was presence of wide spaces within the tubular portion of glands. Moreover, there were foci of cells of gastric glands exhibiting swelling and cytoplasmic vacuolation in between normally looking cells in the lamina propria of the gastric mucosa in both groups B and C. A Statistically significant difference $(p<0.05)$ was observed in histopathological findings between experimental groups $B$ and $C$ as compared with group A (Table II and III). However, no statistically significant difference in histopathological findings $(p>0.05)$ was seen between groups B and $C$ indicating that both low-dose and high-dose Carbaryl are equally as harmful to the gastric mucosa.

\section{DISCUSSION}

The present study aimed to investigate whether carbaryl exerted a toxic effect on gastric mucosa by investigating various morphological and histopathological parameters. Our results revealed a considerable decline in mean body and stomach weight as well as alterations in normal gastric histological architecture after carbaryl administration. Furthermore, the toxic effects of carbaryl were seen to be higher in animals whom received a higher dose implying that the toxicity of carbaryl is dose-dependent.

Being the first reservoir of ingested 

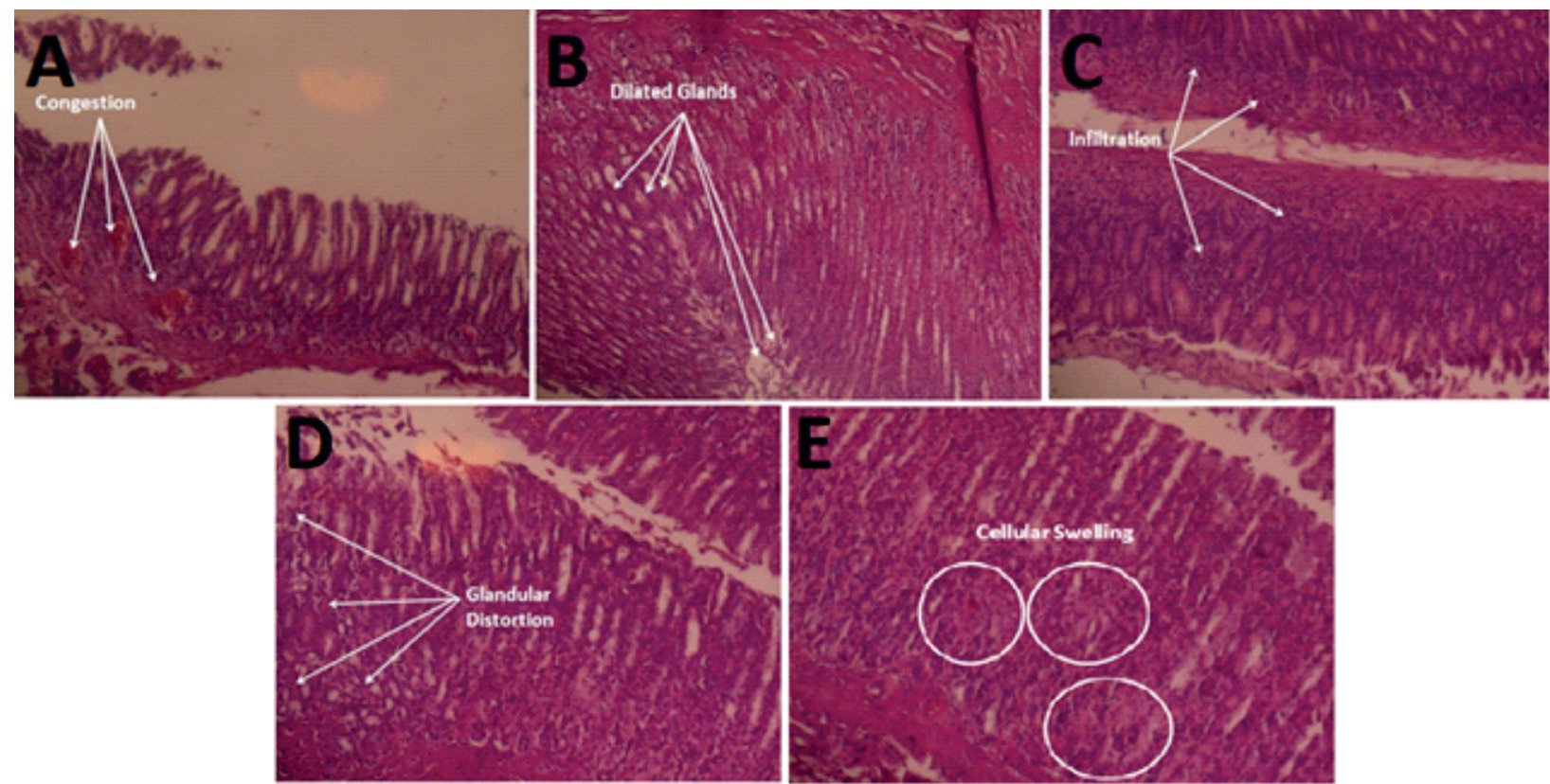

Figure 2: Showing cut section of gastric mucosa of experimental animals (H\&E) x 200. (A) group C rat showing gastric mucosa with multiple areas of venous congestion. (B) group $C$ rat showing gastric mucosa with dilatation of gastric glandular ducts. (C) group $C$ rat showing gastric mucosa with inflammatory cells infiltration. (D) group $C$ rat showing gastric mucosa with distortion of several glands.

(E) group $C$ rat showing gastric mucosa with multiple areas of cellular swelling

food, the stomach is exposed to potentially toxic substances making the gastric mucosa prone to release a considerable amount of reactive oxygen species (ROS). These free radicals eventually cause oxidative stress which has been attributed to causing carbaryl toxicity. ${ }^{22}$

In the present study, carbaryl administration was followed by a marked reduction in body and stomach weight. This weight loss may be attributed to the toxic effects of carbaryl at the cellular level, which includes the release of reactive oxygen species that increase the basal metabolic rate and increase the decoupling oxidative phosphorylation process that is responsible for utilizing the stored body fats for energy. ${ }^{22}$ It could also be due to the anorexia following oral administration of carbaryl, which being the toxic and irritant substance, causes rapid gastric emptying from the stomach and poor absorption of nutrients from the intestinal mucosa. These findings are parallel to the research study conducted by Mahajan $R$, et al. 2013, who had observed weight loss in carbaryl administered experimental group of rats in his study. ${ }^{23}$ Other studies by Mahindra D, et al. 2013 and Hamid S, et al. 2012 also demonstrated similar findings in their experimental rat model as compared to the control group. ${ }^{24,25}$ However, Khanam S, et al. 2017 studied an increase in the mean bodyweight of the experimental broiler chicken after the administration of carbaryl. ${ }^{26}$ It could be due to differences in species of the experimental animal and / or the dose of carbaryl administered.

Carbaryl administration in the present study also showed a decrease in the mean stomach weight of the experimental albino Wistar rats. This can be attributed to carbaryl induced oxidative stress at cellular level mediating alteration in cellular shape, membranous channels, and transportability resulting in loss of viability of cells. This loss in cellular number reduces particular tissue size and ultimately decreases the overall organ (stomach) size. The closest comparison can be made with the research studies conducted by Jorsaraei SGA, et al. 2014 who discovered immunotoxic effects of carbaryl on rats, revealing a decrease in the weight of Thymus and Spleen as compared to the control groups. ${ }^{10}$

The present study also revealed various histopathological alterations in the gastric mucosa of the experimental albino Wistar rats. This can be due to the local effect of carbaryl at cellular level, mediated by the activation of various caspase- 3 proteins, which initiate the executioner phase of cell apoptosis. Çakici Ö, et al, 2017 observed cellular swelling, venous congestion, dilatation of glandular ducts, distortion of the mucosal glands and inflammatory cells infiltration in the gastrointestinal mucosa post carbaryl administration. ${ }^{13}$ Likewise, the above mentioned histopathological changes were also observed by Khudair Z, et al. 2015 in the intestine, kidneys, heart, and lungs of the pigeons. ${ }^{27}$ This indicates the remote adverse effects of ingested carbaryl on distant organs as the metabolites of carbaryl (naphthalene and methylamine) are also toxic to living tissues.

The current study also had certain limitations. Firstly, deficiency of 
resources and time was one of the major constraints. Secondly, the current study only focused on histopathological and gross morphological parameters of stomach of albino Wistar rats. Moreover, grading of histopathological markers was also not performed which may further highlight the dosedependent toxic effects of carbaryl in detail. Therefore; further studies are recommended to assess the various effects of carbaryl, including histopathological grading to evaluate the severity, on other organs as well on serum oxidative and inflammatory markers.

\section{CONCLUSION}

Carbaryl ingestion exerts toxic effects on gastric mucosa causing marked alterations in gastric histological architecture leading to oxidative stress which can be attributed to the main pathway of carbaryl toxicity.

\section{REFERENCES}

I. Mew EJ, Padmanathan P, Konradsen F, Eddleston M, Chang S-S, Phillips $M R$, et al. The global burden of fatal self-poisoning with pesticides 200615: systematic review. J Affect Disord 2017 Sep;21 9:93- I04. DOI: 10.1016/j.jad.2017.05.002.

2. AL-Gehani SA. Effect of sub chronic exposure to Malathion on hematological parameters in the quail. Glob Adv Res J Environ Sci Toxicol 20। 3;2:77-8I.

3. Khan MI, Shoukat MA, Cheema SA, Arif HN, Niazi NK, Azam M, et al. Use, contamination and exposure of pesticides in Pakistan: a review. Pak J Agricul Sci 2020;57( I ): I 3 | -49.

4. Manumati M, Mahindra N. Toxic effects of Carbaryl on the Vasculature of Liver in Adult Albino Rat, Rattus norvegicus. Indian J Forensic Med Toxicol 20 I3;7(2):748. DOI: I 0. $5958 / \mathrm{j} .0973$ 9130.7.2.016.

5. Koshlukova S, Reed A. Carbaryl. In: Wexler, P.(Ed)., Encyclopedia of Toxicology, $3^{\text {rd }}$ edition, vol I. Elsevier Inc., Academic Press, pp.668-672. 2014.
6. Saad M, Shams D, Khan W, ljaz A, Qasim M. Occurrence of selected pesticides and pcps in surface water receiving untreated discharge in Pakistan. J Environ Anal Toxicol 20I 7;7(500):2 I 6I-0525. I000500. DOI: $10.4172 / 2161-0525.1000500$.

7. Wang J-h, Zhu L-s, Liu W, Wang J, Xie $\mathrm{H}$. Biochemical responses of earthworm (Eisenia foetida) to the pesticides chlorpyrifos and fenvalerate. Toxicol Mech Methods 2012 Apr;22(3):236-4I. DOI: 10.3109/15376516.2011.6407|8.

8. Anguiano OL, Vacca M, Araujo MER, Montagna $M$, Venturino A, Ferrari A. Acute toxicity and esterase response to carbaryl exposure in two different populations of amphipods Hyalella Curvispina. Aquat Toxicol 2017 Jul; I88:72-79. D O I : $\quad$ 1 $0.1016 /$ j.aquatox.2017.04.013.

9. Dhouib I, Jallouli M, Annabi A, Marzouki S, Gharbi N, Elfazaa S, et al. From immunotoxicity to carcinogenicity: the effects of carbamate pesticides on the immune system. Environ Sci Pollut Res Int 2016 May;23(I0):9448-58. DOI: 10.1007/s | |356-016-64|8-6.

10. Jorsaraei SGA, Maliji G, Azadmehr A, Moghadamnia AA, Faraji AA. Immunotoxicity effects of carbaryl in vivo and in vitro. Environ Toxicol Pharmacol 2014 Nov;38(3):838-44. DOI: I0.1016/j.etap.2014.09.004.

II. Tariq A. Hazardous impacts of pesticide usage on farmer's health in cotton growing region of district Muzaffargarh, Pakistan. Pacif Int J 2019;2(3): I2-20.

12. Çakıcı Ö. Histopathologic changes in liver and kidney tissues induced by carbaryl in Bufotes variabilis (Anura: Bufonidae). Exp Toxicol Pathol 2015 Mar;67(3):237-43. DOI: I0.1016/j.etp.2014.12.003

13. Çakici Ö. Carbaryl-induced histopathologic alterations in the digestive tract of the Levantine frog, Pelophylax bedriagae (Anura: Ranidae). Toxicol Pathol 2014 Aug;42(6): 1032-40. DOI: 10.1 I77/ 0192623313503517.

14. Muthaiah VPK, Ding D, Salvi R, Roth
JA. Carbaryl induced ototoxicity in rat postnatal cochlear organotypic cultures. Environ Toxicol 2017 Mar;32(3):956-969. DOI: 10.1002/ tox.22296.

15. Çakici Ö. Toxic effects of carbaryl on the histology of testes of Bufotes variabilis (Anura: Bufonidae). Acta Herpetol 20I5; I0(I). DOI: I0.13 I28/Acta_Herpetol- 14780.

16. Çakıcı Ö. Histopathological study of toxic effects of carbaryl on digestive tract of Bufotes variabilis (Anura: Bufonidae). Environ Sci Pollut Res Int20 I 6 Jul;23(I3): I3432-7. DOI: |0.1007/s | |356-016-6529-0.

17. Cakici O, Akat E. Histopathological effects of carbaryl on digestive system of snake-eyed lizard, Ophisops elegans. Bull Environ Contam Toxicol 2012 May;88(5):685-90. DOI: 10.1007/s00 |28-0|2-057|-5.

18. Sengupta P. The laboratory rat: relating its age with human's. Int J Prev Med 2013 Jun;4(6):624-30.

19. Charan J, Kantharia N. How to calculate sample size in animal studies? J Pharmacol Pharmacother 2013 Oct-Dec; 4(4): 303-306. DOI: 10.4103/0976-500X.II9726.

20. Saad SMM AE-A, Abd El-Rahman, Hanan H. Osman. Effect of Prolonged Oral Administration of Carbaryl on Fertility, Liver and Kidney Function of Albino Rats. Annals Agric Sci Moshtohor 2003;4|: |27-|4|.

21. Pant N, Shankar R, Srivastava SP. Spermatotoxic effects of carbaryl in rats. Hum Exp Toxicol 1996 Sep;I5(9):736-8. DOI: 10.1177/ 096032719601500903.

22. Habib K, Kumar S, Manikar N, Zutshi S, Fatma T. Biochemical effect of carbaryl on oxidative stress, antioxidant enzymes and osmolytes of cyanobacterium Calothrix brevissima. Bull Environ Contam Toxicol 201 I Dec;87(6):6I5-20. DOI: 10.1007/ s00I28-0II-04I0-0.

23. Mahajan R, Hamid S, Singh $H$. Histopathological effects of carbaryl on liver in albino rats. Euroasian J 
Hepato-Gastroenterol 2013;33:17. DOI: 10.5005/jp-journals10018-105I.

24. Mahindra N, Manumati M. Effect of Carbaryl on the Histomorphometry of Kidney in Albino Rats. IOSR J Dent Med Sci 2013;5:31-4. DOI: $10.9790 / 0853-0543134$.
25. Hamid S, Mahajan R, Singh H. Carbaryl, a pesticide causes "toxic hepatitis" in albino rats. J Cytol Histol. 20I2;3(4): I 49-54. DOI: $10.4172 / 2157-7099.1000149$.

26. Khanam S. Toxicological Effect on Behaviour and Body Weight of Broiler Chicks Exposed to Carbaryl and Zinc: GRIN Verlag; 2017.

27. Khudair Z. Toxicologic Pathology of Carbaryl in Pigeons in Basrah/ Iraq. Int J Emerg Trends Sci Technol 20I5;2(I):3364-9. DOI:10.18535/ ijetst/v2il I.07.

\section{AUTHORS' CONTRIBUTIONS}

Following authors have made substantial contributions to the manuscript as under:

MSH \& MSB: Conception and study design, acquisition of data, drafting the manuscript, critical review, final approval of the version to be published.

KAM: Analysis and interpretation of data, drafting the manuscript, critical review, final approval of the version to be published.

AA: Study design, acquisition of data, drafting the manuscript, final approval of the version to be published.

SK \& RQ: Acquisition of data, drafting the manuscript, final approval of the version to be published.

Authors agree to be accountable for all aspects of the work in ensuring that questions related to the accuracy or integrity of any part of the work are appropriately investigated and resolved.

CONFLICT OF INTEREST
Authors declared no conflict of interest
GRANT SUPPORT AND FINANCIAL DISCLOSURE
NIL

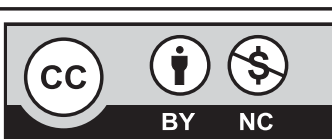

This is an Open Access article distributed under the terms of the Creative Commons Attribution-Non Commercial 2.0 Generic License.

KMUJ web address: www.kmuj.kmu.edu.pk

Email address: kmuj@kmu.edu.pk 